\title{
AN APPROACH TO ONLINE LEARNING USING LEARNING MANAGEMENT SYSTEM IN HIGHER EDUCATION INSTITUTION
}

\author{
Sartika Kurniali \\ School of Information Systems, Bina Nusantara University, Jakarta, Indonesia
}

Received 2014-02-18; Revised 2014-02-19; Accepted 2014-04-03

\begin{abstract}
When higher education institutions want to offer online learning program they need to overcome various constraints. One of them is the system. The Learning Management System (LMS) discussed is a webbased system developed and implemented in-house for a private university with a purpose to enable its new online learning program. The program differs from the regular face to face program since it is dominated with online classes. The LMS was designed and implemented to provide the right solution. The LMS succeed to facilitate students and lecturers in obtaining academic information and learning process anytime, anywhere via the internet. Since most of the time the students don't come to the campus. In this study we explore the findings, discuss issues in the research, suggest how these results may foster improvement and give an input for other higher education institutions.
\end{abstract}

Keywords: Learning Management System (LMS), Online Learning, Learning Process

\section{INTRODUCTION}

One way to improve economy of the society is through increasing the participation number in the education sector. However Indonesia with a population of more than 200 million people, only around $18 \%$ of them are in college, according to Statistics Indonesia (BPS) in 2011. This number is still so low compared to the number in developed nations which is around $40 \%$. This is due to the expensive tuition fee and lack of access for good degree programs in remote areas.

As mentioned, one of the factors of the low percentage of college students compared to the population number is distance. Considering Indonesia is the largest archipelago nation in the world with more than 17,000 islands, more than 416 local languages Bahasa Indonesia as lingua franca and various ethnics. Such conditions posed difficulties for decision makers in making nation-wide-decisions, including in the field of education as witnessed by various educational policy such as state final exams and school attendance.

In this study a LMS used to enable an online learning program in a private university is shown. The findings are gathered from interviews and documents provided by the online learning program.

As one of the biggest private university in Indonesia, BINUS has been in the higher education sector for more than 30 years. And since 2000 the university had the experience of integrating Learning Management System (LMS) as a critical part of their day to day teaching, learning and management process.

They developed their own LMS called BINUS Maya in 2005 which can be accessed through the internet which provide great opportunities to expand the teaching and learning process beyond the classroom.

Based on those facts and improved internet access in Indonesia, BINUS University then developed another LMS which can facilitates even more online engagements.

This new design first offered in 2008 and has been managed by the BINUS Online Learning program. The program offers some majors in the university with cheaper tuition fee but make sure that the student will have the same education quality even with different learning process as the students will go through the same process as their friends in the regular conventional program to graduate. Same curriculum and passing grade are also used. Most of the 
lecturers are also actively teaching in the regular program. So, in the end graduating students can have the same certificate of graduation.

Similar results were also reported by (Abrami et al., 2011) that distance and online learning provide exciting opportunities for not only increasing the reach of education and reducing its cost, but, most important to us, for increasing the quality of teaching and learning.

\section{MATERIALS AND METHODS}

\subsection{Learning Process}

While the regular conventional program organized classes per semester, the online learning program organized the classes per period (3 months). This was to make the students become more focus on completing the courses. Students could complete a maximum of 3 courses per period. So, in a semester, students could still complete pretty much the same number of courses as their peers in the regular conventional program. And since most classes are done online, it was possible to still run classes during long holidays, such as Idul Fitri, Christmas and New Year. The learning process can be seen in Fig. 1.

After admission, new students attended the orientation on campus. New students are given adequate information to kick start their college days and of course being taught on how to use the learning management system since the learning management system will be a hub that ties down the teaching and learning process especially during the online classes.

Each course started with a brief face to face session with the lecturer on campus or a video conference online in the first week of each period.
This then followed by 10 weeks of online classes, where each week, students would be doing the following activities, but not necessary in order:

- Students downloaded the material for that week and learn from it

- Students responded to the lecturer's or classmate's post in the discussion forum

- Students downloaded and did the assignment for that week, whether it was a personal or a team assignment.

- Students participated in video conference if it was scheduled

Asynchronous online courses offered anytime/anywhere learning to the students; whereas, in synchronous online courses, students had the freedom of place but had to login at a specific time. While Virtual classrooms allowed instructors and students to interact online synchronously (Martin et al., 2012).

The activities itself was a combination of both. Activity 1, 2 and 3 were considered as asynchronous learning and activity 4 was considered as synchronous learning.

At the end of each course another face to face session or video conference took place before the exam. On campus sessions held at the weekend. Then the students needed to complete their thesis before graduating.

\subsection{The LMS}

The learning Management Systems (LMS) are webbased systems allowing instructors and/or students to share materials and interact online (Lonn et al., 2011). The LMS developed as a frontend for the whole process located at the program's website where students, lecturers and administrators could accessed it using their own user name.

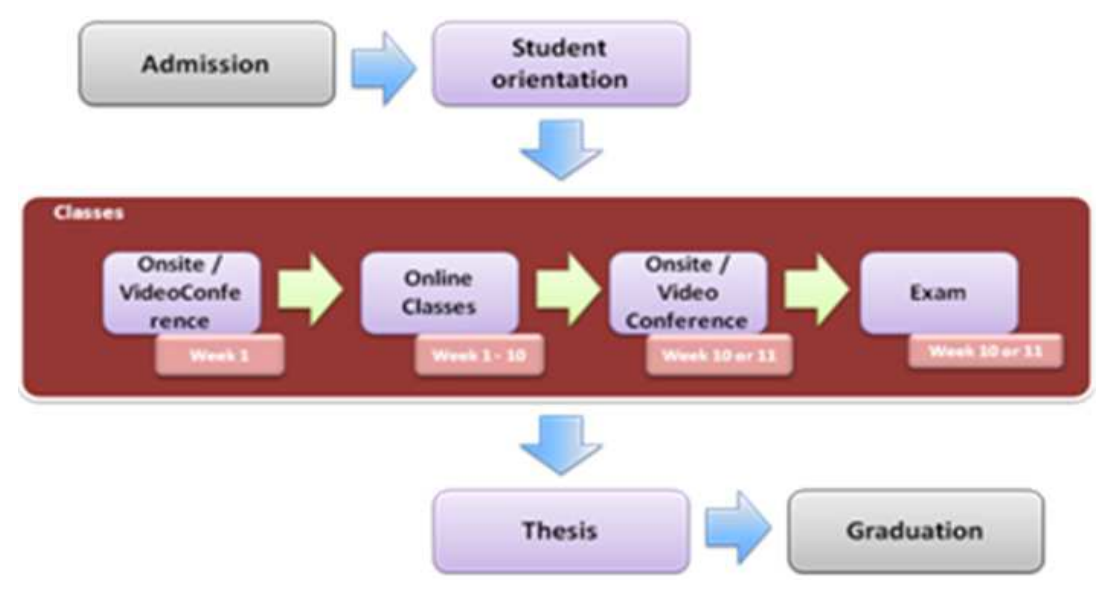

Fig. 1. Learning process 
The most used and valued elements were core LMS functions, including accessing unit information, accessing lecture/tute/lab notes, interacting with unit learning resources, reading online discussions, contacting lecturers/tutors and submitting assignments online (Palmer and Holt, 2009). It should also be noted that online learning did not end with the LMS. On the contrary, there are many online tools to supplement and improve it, including sourcesof information (such as communication tools) and the exchange of experience (García-Peñalvo et al., 2011). Students used these tools outside the LMS to complement their learning experience.

\section{RESULTS}

To serve its purpose to enable the online learning program, the LMS is focused to integrate the learning process inside its features.

All of these activities are done using the LMS through the "My Class" menu. It will show everything that the students need, including course outline, learning materials, discussion forum, assignments, the lecturer's profile and contact, list of classmates and link to participate in the video conference.

\subsection{Learning Materials}

The learning materials can be in the form of PowerPoint presentation, documents, links, or videos.

The students will see the list of topics where all the materials are divided weekly according to the course outline. And by clicking on the name of the topic, students can see details for each topic and download the materials as shown in Fig. 2.

\subsection{Discussion Forum}

The discussion forum was provided for the lecturer and students to discuss each topic weekly. As shown in Fig. 3, the discussion forum supports the interactions between students and lecturer and their classmates just like in a real class.

For students, activities in the discussion forum can add up their grade and for lecturer it is considered as a part of teaching activity. Each post in the discussion forum will show the poster's picture. This helps them to recognize each other because they are rarely meet in person.

\subsection{Assignments}

Students are given weekly assignments. There are two kinds of assignment, personal and team assignments. Each assignment has its own deadline and can be seen on the assignment section as shown in Fig. 4. Of course the students can't submit the assignment if the deadline was already passed.

Each submitted assignment then will be reviewed and scored by the lecturers. In certain cases, if the answers are under qualified the lecturer can give comments and advised the students to correct them in order to be scored. Submitted assignment can't be downloaded by other students. Only lecturers can download the submitted assignment files.

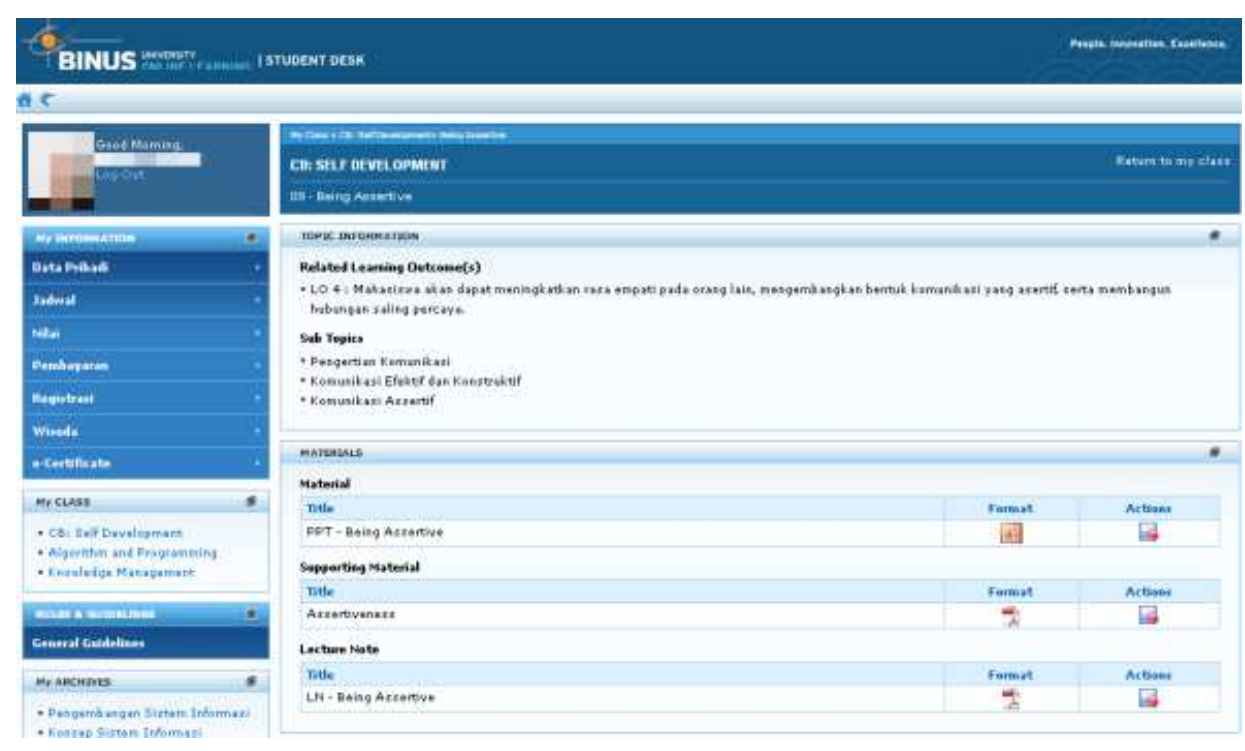

Fig. 2. Learning materials 
Sartika Kurniali / Journal of Computer Science 10 (8): 1517-1521, 2014

\begin{tabular}{|c|c|c|c|c|c|c|}
\hline \multicolumn{7}{|c|}{ DISCUSSION FORUM } \\
\hline \multicolumn{5}{|c|}{ Go to Forum } & \multicolumn{2}{|c|}{ Post new topic to: 18} \\
\hline Room & Subjects & From & Replies & Read & Last Post & Action \\
\hline$\Rightarrow 3$ & mohon ijin kuliah onsite $C B$ tgl $9-2-14$ & Heru Christanto, SS, MM & 1 & 2 & $\begin{array}{l}12 \text { February } 2014 \\
21: 33: 37\end{array}$ & 是 $<$ 国 \\
\hline & No Subject & - & - & - & - & 날 \\
\hline & Hello Team 5 & irma rohimawati & 3 & 16 & $\begin{array}{l}13 \text { December } 2013 \\
14: 24: 44\end{array}$ & ${ }^{A}<$ 国 \\
\hline Fin & Diskusi Minggu ke 10: Building Trustworthiness & FAHMI YUSUF EFFENDI & 53 & 186 & $\begin{array}{l}16 \text { February } 2014 \\
23: 53: 08\end{array}$ & 自 2 国 \\
\hline
\end{tabular}

Fig. 3. Discussion forum

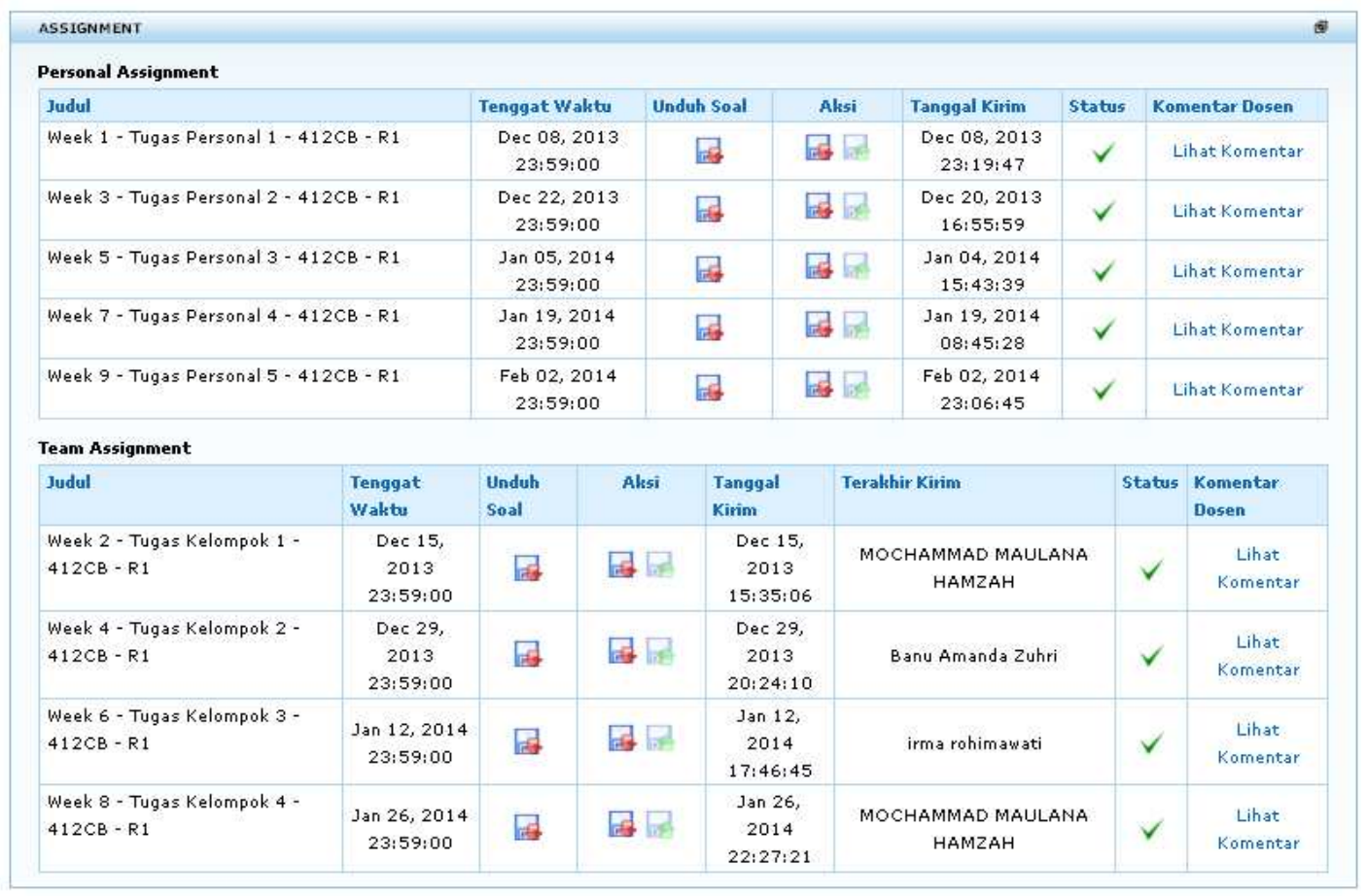

Fig. 4. Assignments

These rules are also applied to team assignment. But for the submission can be done by only one of the team member. Then other team members can see when the assignment was submitted and the lecturer's comment or mark. As now, team members are determined randomly by the system and applied the same in all courses throughout the semester.

After submitting the assignment students can also track their assignment's status. These statuses are in the form of eye catchy icons that inform the students if their assignment was approved, need to be revised, has not been uploaded, waiting to be corrected, or passed the deadline.

\subsection{Video Conference}

The video conference is the only time where the students and lecturer can interact in real time manner. Just like in classroom, usually there will be a lecture and students can give feedback through the chat room. Students can also be assigned to make a presentation to demonstrate their understanding of the course. 


\section{DISCUSSION}

The LMS is a web-based system. Thus, there is no need for installation and can be accessed through a web browser in any kind of device connected to the internet. Either it is smartphone, tablet, or PC. This is convenient because more and more people using devices other that PCs. And information systems that were usually accessed on desktop computers can now be wrapped into an application and accessed on mobile gadgets such as mobile phones. Therefore, these mobile applications should be developed with maximum functionality and practicality (Gunawan and Pardamean, 2013). The LMS also supported lecturers, students and administrators.

The study showed that the learning process design integrated inside the LMS is proven to be suitable for most of students who can be considered as adult learners. Since they are older than the average college students and even have full-time jobs or even their own business prior enrolling to the university. They are back in class to increase their chance to get better position and job. And the program makes it easier for them to do so while maintaining their current jobs, business, family and activities since it's more flexible to attend the classes. The relationship between how instructors use these systems and their students' academic success, utilizing the power of academic data analytics should be considered too (Macfadyen and Dawson, 2010).

On designing system of e-learning, it is considered that one of its major objectives will be to satisfy needs of both students and trainees (Elmetwaly, 2010). This is proved with more students enrolled into the program, new program offerings and increasing number of graduates. Even some overseas workers and expatriates are enrolled into the program.

\section{CONCLUSION}

This approach can reduce the amount of the student tuition compared to the regular conventional program. Students who cannot attend the regular program now can enrol themselves. Available through the internet the LMS not only helps students in their learning process, but also in obtaining the latest academic information anytime and anywhere. In the long run, the LMS could potentially affect the overall university quality and help it gain a competitive advantage over other universities that do not provide online learning program.

This research is limited to the online bachelor's degree programs since the online master's degree programs are in its early stage.
As for future research, there are new features that can be considered to be implemented inside the LMS including class monitoring, online attendance, online documents and online grade submission.There is also the potential of developing a mobile version of the LMS to increase engagements between lecturers and students.

\section{REFERENCES}

Abrami, P., M.R. Bernard, E.M. Bures, E. Borokhovski and R.M. Tamim, 2011. Interaction in distance education and online learning: Using evidence and theory to improve practice. J. Comput. Higher Educ., 23: 82-103. DOI: 10.1007/s12528-011-9043-X

Elmetwaly, H.M., 2010. A system for e-learning processes management. J. Comput. Sci., 6: 689-692. DOI: $10.3844 /$ jcssp.2010.689.692

García-Peñalvo, F.J., M.Á. Conde, M. Alier and M.J. Casany, 2011. Opening learning management systems to personal learning environments. J. Univ. Comput. Sci., 17: 1222-1240. DOI: 10.3217/jucs017-09-1222

Gunawan, K. and B. Pardamean, 2013. School information systems design for mobile phones. J. Comput. Sci., 9: 1140-1145. DOI: 10.3844/jcssp.2013.1140.1145

Lonn, S., S.D. Teasley and A.E. Krumm, 2011. Who needs to do what where? Using learning management systems on residential Vs commuter campuses. Comput. Educ., 56: 642-649. DOI: 10.1016/j.compedu.2010.10.006

Macfadyen, L.P. and S. Dawson, 2010. Mining LMS data to develop an "early warning system" for educators: A proof of concept. Comput. Educ., 54: 588-599. DOI: 10.1016/j.compedu.2009.09.008

Martin, F., M.A. Parker and D.F. Deale, 2012. Examining interactivity in synchronous virtual classrooms. University of North Carolina Wilmington, USA.

Palmer, S. and D. Holt, 2009. Students' perceptions of the value of the elements of an online learning environment: Looking back in moving forward. Interactive Learn. Environ., 18: 135-151. DOI: 10.1080/09539960802364592 